\title{
THE EFFECT OF MELON AND WATERMELON CONCENTRATES ON CONSUMER PROPERTIES OF POLYCOMPONENT DAIRY DESSERT
}

\author{
Ivan Fyodorovich Gorlov, Irina Vazhayena Mgebrishvili, Marina Ivanovna Slogenkina, \\ Natalya Ivanovna Mosolova, Irina Alexandrovna Tarasova
}

\begin{abstract}
A full balanced nutrition is a necessary condition for a person's normal physical and mental development, resistance to the effects of adverse environmental factors and strengthening immunity, which is of particular importance in the bad ecological situation in the world. Providing the population with high-quality bio-functional food is an important state task, the fulfillment of which is the key to the health of the nation, and ultimately ensures the security of the country. One of the effective ways to prevent and treat various diseases is the development of a new generation of functional dessert products with dietary properties. As a basis, there has been a principle considered, i.e., the high nutritional, biological value and physiological activity of the product are predetermined by the high quality of the raw materials. The article analyzes the state of the dairy industry at the present stage. The efficiency of melon and watermelon concentrates in the production of multicomponent dairy dessert has been substantiated. The positive effect of the tested concentrates on the structural and mechanical properties of the jelly part of the dessert, organoleptic characteristics and nutritional value of the product has been established. The optimal concentration of the gelling agent in the jelly has been determined. There were some conducted experiments aimed at maximum reducing of the gelling agent's weight fraction in the product.
\end{abstract}

Keywords: milk dessert; whey; jelly; carrageenan; melon and watermelon

\section{INTRODUCTION}

At the present stage of the food industry development, the whey as the main raw material has been a research subject for a number of scientific schools in the USA, Great Britain and Japan (Faryabi et al., 2009; Yang, Irudayaraj and Sakhamuri, 2001). Their research studies were mainly aimed at functional properties of whey and its feasibility, mainly in clinical nutrition (Ghosh and Playford, 2003). Whey proteins are used to prepare baby foods, since their composition is more similar to the composition of mother milk proteins (Gorlov et al., 2015).

Today, one of the promising areas for the introduction of whey products is the market for dairy desserts. It is considered to be one of the most dynamically developing and marginal. Over the four pre-crisis years, it grew by more than 30\% (Mgebrishvili et al., 2013a). The reason for this was not only the high demand for dairy desserts, but also the constantly expanding assortment. Original milk desserts enjoy high demand, their consumer properties are formed depending on the type and quality of the raw materials used (Khramtsov and Vasilisin, 2004). In the Lower Volga region, there are considerable regional resources of watermelon and melon that may be involved in the production of dairy products with a predetermined composition and consumer properties (Mgebrishvili and Gorlov, 2012). In solving this problem, a promising direction is the development of innovative functional complex dairy desserts with high nutritional and biological value.

The combined use of by-products of dairy processing production and regional plant raw materials offers exciting possibilities for creating new types of dairy products with preventive properties, provided their cost is reduced (Mgebrishvili et al., 2013b).

The research conducted meets the current trends in the development of the dairy industry. The most important trend is the development of innovative technologies aimed at expanding the range and improving the quality of output products. An important aspect here is the use of secondary dairy raw materials, in particular, whey, which not only increases the biological value of the product, but also reduces its cost price (Gorlov, Mosolova nad Korotkova, 2012). In relation to the problem, it becomes appropriate to use melon and watermelon concentrates as functional fillers in recipes for dairy desserts. New types of fillers have many useful properties, which makes the dessert functional. 


\section{Scientific hypothesis}

We are expecting: watermelon and melon fillers has significant effect on the process of structure formation.

\section{MATERIAL AND METHODOLOGY}

The research material contained raw ingredients, namely, goat cheese, unsalted cheese whey, watermelon (Citrúllus lanátus), melon (Cucumis melo), sponge cake with flaxseed and produced milk dessert itself.

Evaluation of the quality of the raw materials and product was conducted according to the following generally accepted methods, i.e., titrable acidity by the titrimetric method according to GOST 3624-92; density by the areometric method according to GOST R 54758-2011; and weight fraction of dry matter by the drying method according to GOST 3626-73. The optimal dose of the thickener in the jelly part of the dessert was established on the basis of the system's viscosity data obtained by the method of viscometry using an SV-100 vibration viscometer. With respect to the task, a low-cost technology for the production of melon and watermelon concentrates based on the thickening method was proposed. This technology allowed promising use of inexpensive plant material in recipes of complex dairy products.

Milk dessert "Sankarini" consisted of three layers. The first layer was pieces of airy sponge cake enriched with flax seed additive (Edwards, 2009). The implementation of the agenda aimed at ensuring healthy nutrition of the population in the country made scientists pay attention to flax seed as a source of biologically active substances (Buldakov, 2001).

The second layer was a jelly layer made of whey divided into two figured parts (Crus, Tinyakov and Fofanov, 1986). One part was filled with watermelon, the other one with melon. The color of the jelly was due to the natural pigments of the filler, i.e., concentrated mashed watermelon or melon pulp, condensed in the process of vacuum evaporation. Desalted whey was used as a base for jelly. Carrageenan that is a polysaccharide derived from red seaweed was used as a gelling agent (Gomes et al., 2013). Pieces of the jelly phase had a delicate sweet taste with the aroma characteristic of watermelon or melon, respectively.

The third layer was the so-called "cheese cream" made from soft goat cheese (Krupin, 2009). The functional properties of this component were confirmed by the wellknown effect of goat milk that is inherently identical to female milk, as it contains a lot of $\beta$-casein. Goat milk contains more sialic acid that is included in the structure of the body's immunity barriers. The fat globules in goat milk are much smaller than in cow's milk, therefore they are better digested by the body (Mgebrishvili et al., 2013c).

The textures and tastes of all three parts of the product were brilliantly combined with the undoubted functionality of both individual ingredients and the whole Sankarini dessert (Ajewole et al., 1999). To analyze the effect of watermelon and melon concentrates in the production of a multicomponent dairy dessert based on whey, it was necessary to investigate changes in the structural and mechanical properties of jelly depending on the number of thickener doses applied.

\section{Statistic analysis}

Experimental studies presented in the article are processed by methods of variation statistics with the determination of the criterion of reliability of the difference according to the t-test Fisher criterion using the program STATISTIKA-10.

\section{RESULTS AND DISCUSSION}

At the first stage of experimental studies, three laboratory samples of jelly without fillers were obtained. The recommended amount of carrageenan needed for gelling varies in over the range of $0.02-0.1 \%$ (Basiria et al., 2018).

The proportion of gelling agent in the samples obtained was $0.05,0.075$ and $0.1 \%$. Dry carrageenan was injected into the whey. One hour later, which was required for gelling, the dynamic viscosity of each sample was determined. According to the data obtained, the jelly samples with a carrageenan concentration of 0.05 and $0.075 \%$ at a temperature of about $20^{\circ} \mathrm{C}$ had a coefficient of dynamic viscosity of water of $0.15 \mathrm{~Pa} . \mathrm{s}$, that is, they were not defined as a viscous system. So, only the sample with a concentration of $0.1 \%$ carrageenan was identified as a viscous system.

Today, scientists in different countries found that watermelon and melon contain high levels of fiber and pectin (Balaghi and Senge, 2014; Sethi et al., 2016; Gul et al., 2016; Karnopp et al., 2017). In this regard, it was suggested that using watermelon and melon concentrates as fillers would not only add preventive properties to the product, but also minimize the concentration of carrageenan and also make maximum use of secondary raw materials.

At the second stage of the experimental studies, two model samples of jelly were developed, i.e., with watermelon and melon concentrates. The concentration of carrageenan in these samples was reduced to $0.075 \%$. The values of the dynamic viscosity coefficients were obtained and best corresponded the jelly structure (Table 1).

When comparing the values of the dynamic viscosity coefficients for jelly samples without melons concentrates and with the concentrates, it could be seen that the fillers helped not only reduce the carrageenan concentration, but also increase the stability of the jelly system. These models are non-linear, statistically significant $\left(\mathrm{F}_{\text {observe }}>\mathrm{F}_{\text {table }}\right)$ high decreasing linear relationship and a good value of the determination coefficient, characterizing a high proportion of the variance of the effective feature (viscosity), can be explained by regression to the total variance. Show almost the same close linear relationship and viscosity rate. (Figure 1).

At the third stage of the experimental studies, to minimize the concentration of the gelling agent, locust bean gum was proposed for this purpose. This type of stabilizers in combination with carrageenan exhibits synergistic properties and enhances the effect of the latter. Similarly, to the previous test, two model samples of jelly were developed: with watermelon and melon concentrates. The gelling agents' (carrageenan and locust bean gum) concentrations in these samples were reduced to $0.025 \%$. These models are also linear and statistically significant $\left(F_{\text {observe }}>F_{\text {table }}\right)$ with a high decreasing linear relationship and a good value of the determination coefficient characterizing the high proportion of the variance of the resultant trait (viscosity), explained by regression, in the 


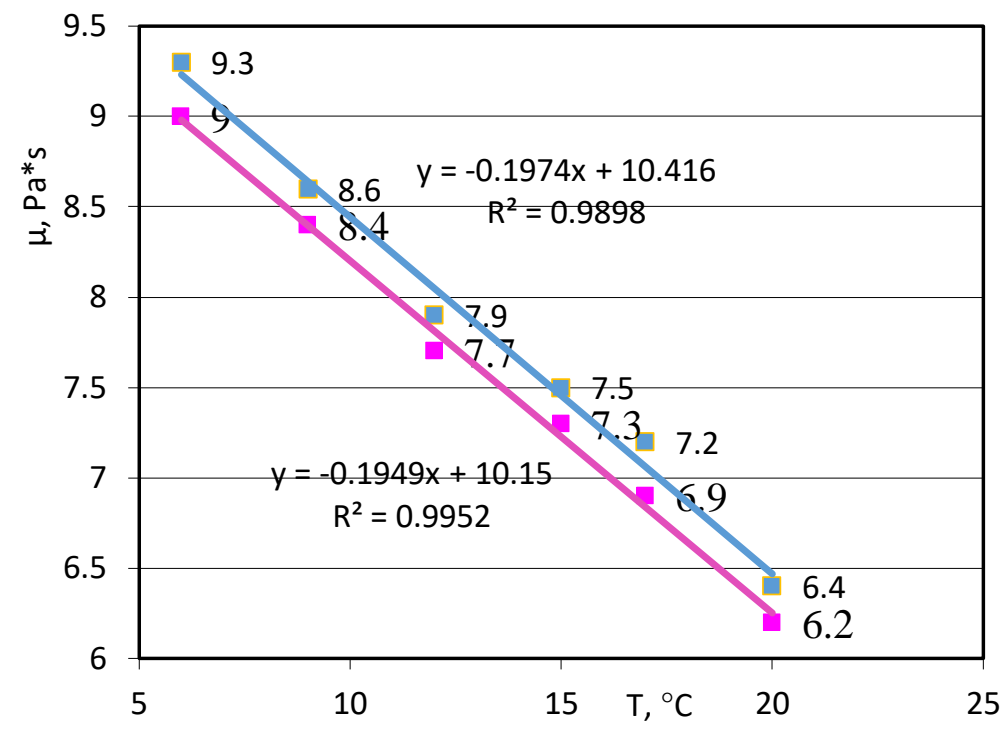

- Watermellon jelly

Mellon jelly

Figure 1 Influence of watermelon and melon fillers on the viscosity of jelly samples with a concentration of $0.075 \%$ carrageenan.

Table 1 Dynamic viscosity of jelly with fillers, with carrageenan concentration being of $0.075 \%$

\begin{tabular}{cccc}
\hline \multirow{2}{*}{ Experience \# } & $\begin{array}{c}\text { Sample's } \\
\text { temperature, }{ }^{\circ} \mathbf{C}\end{array}$ & \multicolumn{2}{c}{ Dynamic viscosity coefficient [eta], Pa.s } \\
\cline { 3 - 4 } & 6 & melon jelly & watermelon jelly \\
\hline 1 & 9 & 8.9 & 8.6 \\
3 & 12 & 7.54 & 8.2 \\
4 & 15 & 7.82 & 6.44 \\
5 & 17 & 6.9 & 6.98 \\
6 & 20 & 6.2 & 6.66 \\
\hline
\end{tabular}

Table 2 The coefficients of dynamic viscosity jelly with fillers, with gelling mixture concentration being of $0.025 \%$.

\begin{tabular}{cccc}
\hline \multirow{2}{*}{ Experience \# } & Sample's temperature, ${ }^{\circ} \mathbf{C}$ & Dynamic viscosity coefficient [eta], Pa.s & welon jelly \\
\cline { 3 - 4 } & 6 & 9.26 & 9.02 \\
2 & 9 & 8.6 & 8.44 \\
3 & 12 & 7.9 & 7.66 \\
4 & 15 & 7.46 & 7.34 \\
5 & 17 & 7.1 & 6.86 \\
6 & 20 & 6.4 & 6.2 \\
\hline
\end{tabular}

Table 3 Organoleptic characteristics of the dessert's jelly part.

\begin{tabular}{lc}
\hline \multicolumn{1}{c}{ Indicator } & Feature \\
\hline Appearance & Figured transparent pieces with glitter, keeping the shape \\
Color & Pink, yellow, characteristic of fillers \\
Smell & Pleasant, characteristic of fillers \\
Consistency & Dense, resilient, gelatinous \\
Taste & Sweet, characteristic of fillers \\
\hline
\end{tabular}

total variance. Show almost the same close linear relationship and viscosity rate.

The values of the dynamic viscosity coefficients were obtained and best corresponded to the jelly structure (Table 2 ). When comparing the values of the dynamic viscosity coefficients for jelly samples with a carrageenan concentration of $0.075 \%$ and a gelation mixture concentration of $0.025 \%$, it was clear that the data from the two experiments were almost identical with a considerable decrease in the proportion of gelling agent in the second case (Figure 2). 
Table 4 Physical and chemical indicators of jelly samples.

\begin{tabular}{lll}
\hline \multirow{2}{*}{ Indicator } & Feature & \\
\cline { 2 - 3 } & melon jelly & watermelon jelly \\
\hline $\begin{array}{l}\text { Weight fraction of dry substances, \%, not less } \\
\text { than }\end{array}$ & $40 \pm 0.5$ & $38 \pm 0.5$ \\
Acidity, ${ }^{\circ} \mathrm{T}$, no more than & 20 & 20 \\
\hline
\end{tabular}

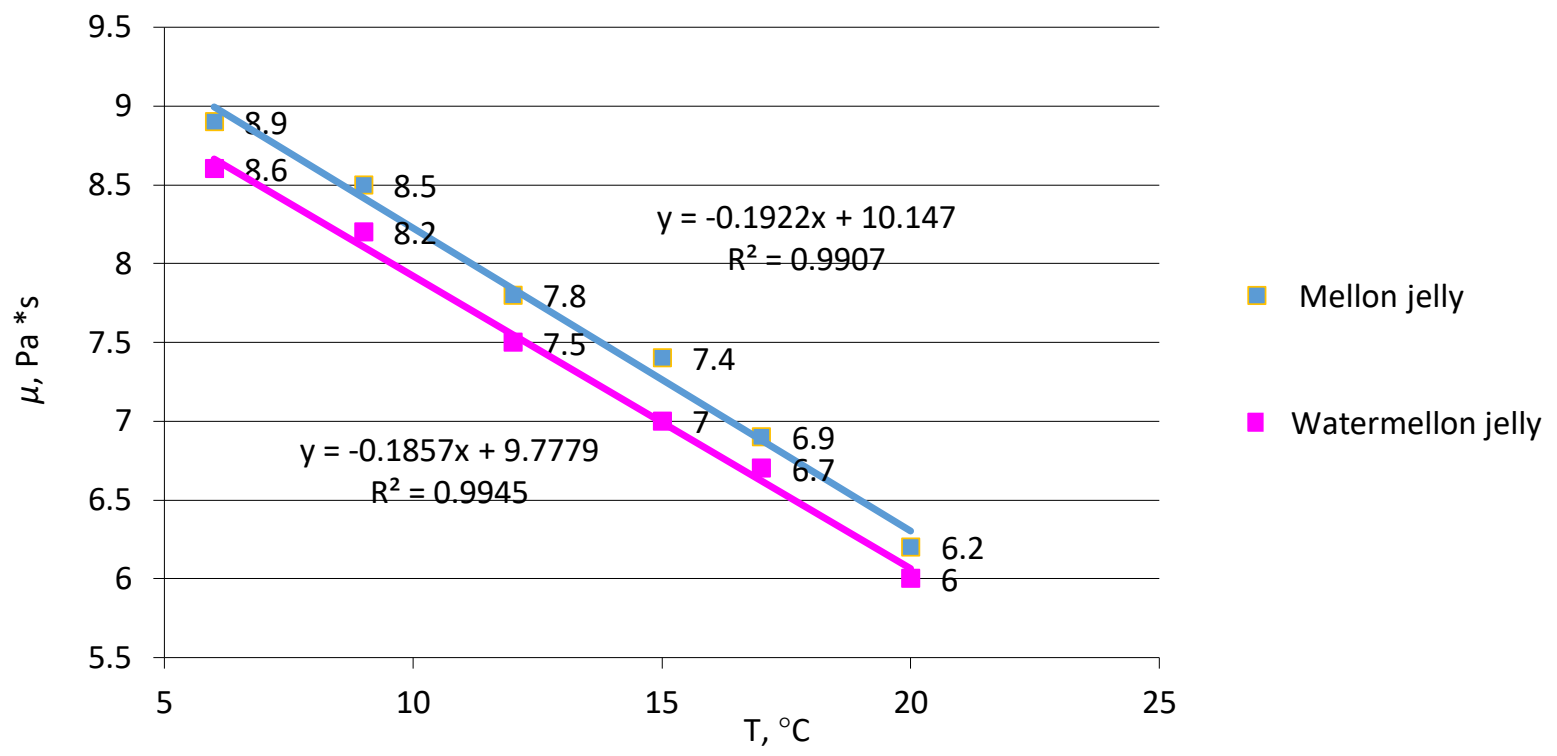

Figure 2 Effect of watermelon and melon fillers on the viscosity of jelly samples with the concentration of the mixture of gelling agents $0.025 \%$.

At the fourth stage of the experimental studies, an organoleptic assessment of the jelly phase of the milk dessert was made in terms of appearance, color, smell and texture. The objects of the study were model samples of jelly with watermelon and melon fillers obtained using a mixture of carrageenan and locust bean gum in an amount of $0.025 \%$ (Table 3).At the fifth stage of the experimental studies, the physicochemical parameters of the jelly part of the dessert, in particular the acidity and weight fraction of dry substances, were determined. For this purpose, four laboratory samples of jelly were obtained, two with watermelon and two with melon fillers. Physicochemical characteristics of the jelly samples are shown in Table 4.

\section{CONCLUSION}

The positive effect of melon concentrates on the process of structure formation of whey is scientifically substantiated and practically proved.

Studies have found that to ensure optimal conditions of structure formation in a mixture of whey and melon concentrates, a dose of a mixture of gelling agents in an amount of $0.025 \%$ of the total weight is required.

To optimize the technological parameters in the direction of ensuring maximum yield of jelly, it is advisable to partially replace carrageenan with carob gum, which in this combination shows synergistic properties.

\section{REFERENCES}

Ajewole, I. A., Ozo, O. N., Ezenweke, L. O., Okoli, E. 1999. Enrichment of pregelatinized cocoyam flour with melon seed protein concentrate as an instant food gel. Discovery and Innovation, vol. 11, no. 3-4, p. 185-188. https://doi.org/10.4314/dai.v11i3.15552

Balaghi, S., Senge, B. 2014. Structural development of semisolid dairy desserts influenced by hydrocolloids and temperature: Rheology and particle size distribution. International Dairy Journal, vol. 39, p. 184-192. https://doi.org/10.1016/j.idairyj.2014.06.007

Basiria, S., Haidarya, N., Shekarforousha, S. S., Niakousari, M. 2018. Flaxseed mucilage: A natural stabilizer in stirred yogurt. Carbohydrate Polymers, vol. 187, p. 59-65. https://doi.org/10.1016/j.carbpol.2018.01.049

Buldakov, A. S. 2001. Food supplements: a reference book. Moscow, Russia : DeLi, 436 p. ISBN 5-7443-0023-6.

Crus, G. N., Tinyakov, V. G., Fofanov, Y. F. 1986. Milk technology and dairy industry equipment: study manual. Moscow, Russia : Agropromizdat, 280 p. ISBN 5-9532-00811.

Edwards, B. 2009. Caramels, fondants and jellies as centers and fillings. In Talbot, G. Science and Technology of Enrobed and Filled Chocolate, Confectionery and Bakery Products. Cambridge, UK : Woodhead Publishing, p. 123-151. ISBN 9781845696436. https://doi.org/10.1533/9781845696436.1.123

Faryabi, B., Mohr, S., Onwulata, C. I., Mulvaney, S. J. 2009. Foods Containing Whey Proteins. In Onwulata, CH. I., Huth, 
P. J. Whey Processing, Functionality and Health Benefits. Hoboken, USA : John Wiley \& Sons, p. 213-226. ISBN 9780813803845. https://doi.org/10.1002/9780813803845

Ghosh, S., Playford, R. J. 2003. Bioactive natural compounds for the treatment of gastrointestinal disorders. Clinical Science, vol. 104, no. 6, p. 547-556. https://doi.org/10.1042/CS20030067

Gomes, J. J. L., Duarte, A. M., Batista, A. S. M., de Figueiredo, R. M. F., de Sousa, E. P., de Souza, E. L. 2013. Physicochemical and sensory properties of fermented dairy beverages made with goat's milk, cow's milk and a mixture of the two milks. LWT Food Science and Technology, vol. 54, no. 1, p. 18-24. https://doi.org/10.1016/j.lwt.2013.04.022

Gorlov, I. F., Mosolova, N. I., Korotkova, A. A. 2012. New in the production of functional products from goat milk. Bulletin of the Russian Academy of Agricultural Sciences, vol. 4, p. 16-18.

Gorlov, I. F., Mosolova, N. I., Zlobina, E. Y., Pryanichnikova, N. S., Randelin, D. A., Fedulova, L.V. 2015. Development and implementation of innovative technologies of production, processing and creation of competitive meat and dairy products of a new generation. Volgograd, Russia : Volgograd Scientific Publishing House, 151 p. ISBN 978-500072-111-7.

GOST 3624-92. Milk and milk products. Titrimetric methods of acidity determination.

GOST 3626-73. Milk and milk products. Methods for determination of moisture and dry substance.

GOST R 54758-2011. Milk and milk products. Methods for determination of density.

Gul, K., Singh, A. K., Jabeen, R. 2016. Nutraceuticals and Functional Foods: The Foods for the Future World. Critical Reviews in Food Science and Nutrition, vol. 56, p. 2617-2627. https://doi.org/10.1080/10408398.2014.903384

Karnopp, A. R., Oliviera, K. G., Forville de Andrade, E., Postingher, B. M., Granato, D. 2017. Optimization of an organic yogurt based on sensorial, nutritional, and functional perspectives. Food Chemistry, vol. 233, p. 401-411. https://doi.org/10.1016/j.foodchem.2017.04.112

Khramtsov, A. G., Vasilisin, S. G. 2004. Reference technologist dairy production. Technology and recipes. Products from skimmed milk, buttermilk and whey vol. 5. StPetersburg, Russia : GIORD, 576 p. ISBN 5-901065-47-6.

Krupin, A. V. 2009. The main patterns of structure formation in whey under the influence of gelling agents. Food industry: science and technology, vol. 3, p. 40-46.

Mgebrishvili, I. V., Gorlov, I. F. 2012. Parfait from goat milk using melon crops concentrates. In Technologies and healthy food. Functional foods: Proceedings of anniversary $X$ scientific-practical. conf. with Intern. Participation. Moscow, Russia, p. 179-182.

Mgebrishvili, I. V., Gorlov, I. F., Selezneva, E. A., Korotkova, A. A. 2013a. Milk dessert Sankarini as a functional product of the new generation. Innovative technologies in the production and processing of agricultural products in the conditions of the WTO: Proceedings of international scientificpractical Conf. Volgograd, Russia : Volga Region Research Institute of Manufacture and Processing of Meat-and-Milk Production, p. 324-327.

Mgebrishvili, I. V., Selezneva, E. A., Korotkova, A. A., Gorlov, I. F. 2013b. Functional polycomponent dessert product. Actual problems of development of the agro-industrial complex of the Caspian sea region. Elista, Russia : Kalmyk State University, p. 61-62.
Mgebrishvili, I. V., Selezneva, E. A., Korotkova, A. A., Gorlov, I. F. 2013c. Efficiency of application of melon concentrates in the formulation of a multicomponent dairy dessert. Storage and processing of agricultural raw materials vol. 8, p. 44-45.

Sethi, S., Tyagi, S. K., Anurag, R. K. 2016. Plant-based milk alternatives an emerging segment of functional beverages: a review. Food Sci Technol., vol. 53, no. 9, p. 3408-3423. https://doi.org/10.1007/s13197-016-2328-3

Yang, H., Irudayaraj, J., Sakhamuri, S. 2001. Characterization of Edible Coatings and Microorganisms on Food Surfaces Using Fourier Transform Infrared Photoacoustic Spectroscopy. Applied Spectroscopy, vol. 55, no. 5, p. 162-170. https://doi.org/10.1366/0003702011952370

\section{Acknowledgments:}

The work was supported by the Russian Foundation for Basic Research, project no. 15-16-10000, SSI NIIMMP "Development and scientific substantiation of new approaches to the production of livestock raw materials and increasing the biological value of socially important products based on modern biotechnological and molecular genetic methods". Grant sponsors were not directly involved in the development, analysis, or writing of this article.

\section{Contact address:}

*Ivan Fyodorovich Gorlov, Volga Region Research Institute of Manufacture and Processing of Meat-and-Milk Production, Rokossovsky Str., 6, Volgograd, 400131 Russia; Volgograd State Technical University, Lenin Avenue 28, 400050 Volgograd, Russia, Tel: +78442391048,

E-mail: nniimmp@mail.ru

ORCID: https://orcid.org/0000-0002-8683-8159

Irina Vazhayena Mgebrishvili, Volgograd State Technical University, Lenin Avenue 28, 400050 Volgograd, Russia, Tel. +79610789402,

E-mail: ira-06@inbox.ru

Marina Ivanovna Slozhenkina, Volga Region Research Institute of Manufacture and Processing of Meat-and-Milk Production, Rokossovsky Str., 6, Volgograd, 400131 Russia; Volgograd State Technical University, Lenin Avenue 28, 400050 Volgograd, Russia, Tel: +79047729999,

E-mail: niimmp@mail.ru

ORCID: https://orcid.org/0000-0001-9542-5893

Natalya Ivanovna Mosolova, Volga Region Research Institute of Manufacture and Processing of Meat-and-Milk Production, Rokossovsky Str. 6, Volgograd, 400131 Russia, Tel.: +79033735182,

E-mail: natalyniimmp@mail.ru

Irina Alexandrovna Tarasova, Volgograd State Technical University, Lenin Avenue 28, 400050 Volgograd, Russia, Tel. +79272581659,

E-mail: irinka_ta@mail.ru

Corresponding author: * 